Yu.M. Vasetsky, I.L. Mazurenko, S.L. Bondarevskyi

\title{
PARAMETRIC ANALYSIS AND STRAY FIELDS OF TOROIDAL SUPERCONDUCTING MAGNETIC ENERGY STORAGE
}

\begin{abstract}
Purpose. To carry out a parametric analysis of superconducting toroidal magnetic systems with a discrete winding, establishing the possibility of using an idealized model in the form of a toroidal current surface and an approximate method for determining the level of fields of scattering of a real magnetic system. Methodology. The calculation of the distribution of the magnetic flux density in the winding, the field of scattering and energy of the storage's field was carried out using asymptotic methods for solution of the problems of electrodynamics in systems with massive curvilinear conductors with current. An iterative calculation procedure was used to determine the dimensionless characteristics. Results. The dimensionless characteristics of a toroidal magnetic system with a winding in the form of individual superconducting coils of circular shape are calculated. The results are obtained depending on the value of the storage's energy capacity for various values of the relative radial size of the torus. For a toroidal superconducting storage device with energy capacity of $450 \mathrm{MJ}$, enough to perform the function of damping irregular oscillations of power transmitted over the transmission line, magnetic fields of scattering are calculated for different numbers of coils and torus section sizes. Originality. Based on a comparison of the values of dimensionless characteristics calculated for a system with individual coils, and for an idealized mathematical model of a continuous current surface, it was established that the relative deviation of the dimensionless characteristics does not exceed $10 \%$. In contrast to the idealized model, the magnetic field of a toroidal system composed of individual coils spreads beyond the toroidal surface and decreases the faster, the smaller the relative radial sectional size of the torus, the greater the number of coils used and the closer they are to each other. Practical value. The results obtained for dimensionless characteristics allow to conclude that the idealized model can be used at the first stage of the development of a superconducting inductive storage. The estimation of the field of scattering can be made on the basis of a simple model of unidirectional current filaments. References 15, figures 7.
\end{abstract}

Key words: superconducting magnetic energy storage, parametric analysis, stray magnetic field.

Розглянуто надпровідну тороӥдальну магнітну систему з котушками круглоӥ форми. Досліджено можливість використання ідеалізованої математичної моделі у вигляді суцільної струмової поверхні для проведення параметричного аналізу магнітних систем з обмеженою кількістю окремих котушок. На основі порівняння величин безрозмірних характеристик, розрахованих для системи з окремими котушками $і$ для ідеалізованої моделі, встановлено, що відносне відхилення не перевищує 10 \%. Отримано залежсності магнітного поля розсіювання для магнітної системи енергосмністю 450 МДж від відносного розміру перерізу тора $і$ кількості котушок. Виконано оцінку характерної відстані від тороїдальної поверхні, на якій спадає магнітне поле розсіювання. Бібл. 15 , рис. 7.

Ключові слова: тороїдальний надпровідний індуктивний накопичувач, параметричний аналіз, магнітне поле розсіювання.

Рассмотрена сверхпроводящая тороидальная магнитная система с катушками круглой формы. Исследована возможность использования идеализированной математической модели в виде сплошной токовой поверхности для проведения параметрического анализа магнитных систем с ограниченным количеством отдельных катушек. На основе сравнения величин безразмерных характеристик, рассчитанных для системы с отдельными катушками и для идеализированной модели, установлено, что относительное отклонение не превышает 10 \%. Получены зависимости магнитного поля рассеяния для магнитной системы энергоемкостью 450 МДж от относительного размера сечения тора и количества катущек. Выполнена оценка характерного расстояния от тороидальной поверхности, на котором убывает магнитное поле рассеяния. Библ. 15, рис. 7.

Ключевые слова: тороидальный сверхпроводящий индуктивный накопитель, параметрический анализ, магнитное поле рассеяния.

Introduction. Recently, there is an increase in the interest of researchers to the possibility of using superconducting magnetic energy storage (SMES) to increase the sustainability of power systems and improve power quality as a promising high-tech way to solve a number of problems in the power industry [1-3]. This interest is due, among other things, to the successes in the use of superconducting magnetic systems with large accumulated energy in large-scale physical facilities for controlled thermonuclear fusion [4-6].

Investigations to identify areas of potential effective use of SMES to address the issues of improving the reliability and manageability of power transmission in the power systems of Ukraine have shown that it can be economically feasible to use them in the following areas: ensuring the dynamic stability of power plants, damping irregular fluctuations in the power system load, short-term emergency frequency regulation large disturbances [7]. The values of SMES energy capacity for use in the specified areas of the power industry are approximately in the range of $100-10,000$ MJ. For these applications, there are both several operating SMES and research-based SMES projects, taking into account specific power systems and their operating modes $[8,9]$. Regarding the feasibility of SMES in the specified energy capacity range, the fact add optimism that the magnetic energy storage of toroidal configuration, intended for use in large-scale physical installations, primarily in the field of controlled thermonuclear fusion, have been developed, created and operated for many years.

To be able to use SMES in the power industry, one of the main factors is lower cost compared to alternative solutions. Here, an important characteristic is the

(C) Yu.M. Vasetsky, I.L. Mazurenko, S.L. Bondarevskyi 
necessary mass-dimensional parameters of SMES and, above all, its magnetic system. These parameters usually include the following [10,11]: dimensions - large radius $R$ and dimensions of the torus section: volumes (masses) of the material of the superconducting winding $V_{s c}$ and the structural material of the holding mechanical system $V_{s t}$. An important characteristic is also the field of scattering of the toroidal system.

When developing a superconducting storage device, the following parameters are initial: the energy of the magnetic field of the storage device $W$, which is necessary for its corresponding application; the properties of a superconducting material - the permissible maximum values of the magnetic flux density on the winding $B_{m}$ and current density in the conductors $j_{m}$; the material properties of the mechanical holding system - the permissible values of mechanical stresses $\sigma$.

At carrying out a parametric analysis, a relationship is established between the initial and mass-dimensional parameters of the magnetic energy storage, and investigations are performed on the effect of the configuration, in this case of a toroidal magnetic system, on the mass-dimensional parameters. Such investigations are adequately performed using an idealized mathematical model in the form of a current surface for tori with sections of circular, D-shaped, and racetrack shapes [4, 10]. At the same time, real superconducting toroidal storages are made as a system of individual coils, the axial lines of which are located on a toroidal surface. The parameters of such systems differ from the results of the calculation according to the idealized model [11, 12]. In addition, if there are no fields of scattering for an idealized torus, in a real system the magnetic field extends beyond the toroidal surface $[4,13]$.

The goal of the work is to carry out a parametric analysis of superconducting toroidal magnetic systems with a discrete winding, to establish the possibility of using an idealized model in the form of a toroidal current surface, and also to investigate magnetic fields of scattering and use an approximate method to determine them in a magnetic system composed of individual coils.

The influence of the discreteness of the winding on the mass and dimensional parameters of the toroidal storage. Analysis of the feasibility of estimating the mass and dimensional parameters of the magnetic system with a limited number of coils based on the use of the calculation results by an idealized model can be performed by comparing the data obtained by these models. It is believed that magnetized media are absent.

Figure 1 shows a system of $N=14$ individual coils in its section by the $x O y$ plane, in which the rotary axis of the torus lies. In this investigation, it is assumed that the section of each coil has the shape of a rectangle with sides $\Delta$ and $h_{c}$ and does not change along the perimeter of the coil. The intersection lines of the toroidal surface by the $x O y$ plane are shown by dotted circles with the smallest and largest radii $\rho_{1}$ and $\rho_{2}$.

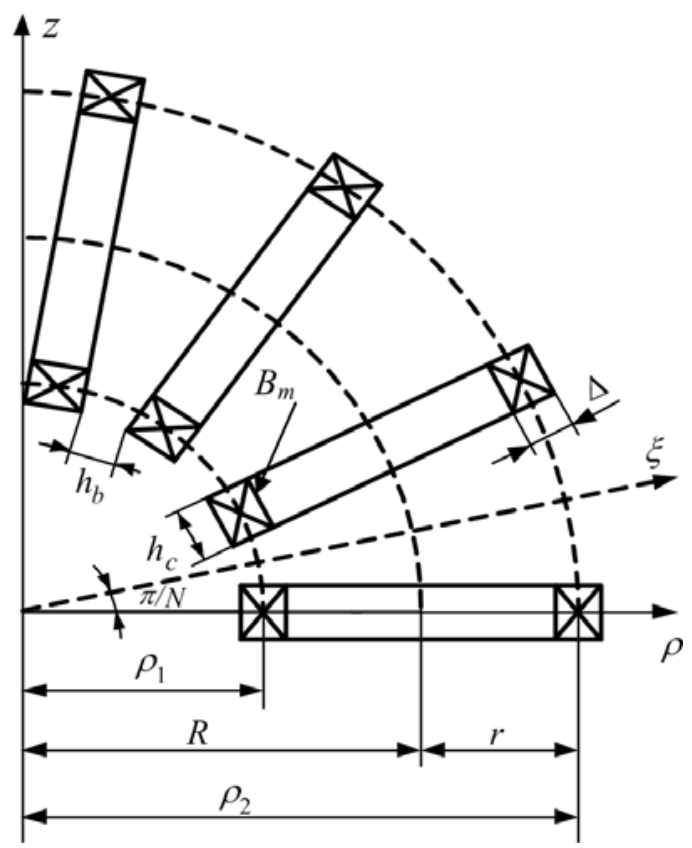

Fig. 1. Toroidal system with limited number of coils

To find the relations between the dimensional initial and mass-dimensional parameters, we represent the maximum value of the magnetic flux density at a certain point of the winding as

$$
B_{m}=\frac{\mu_{0} I}{2 \pi R} k_{B},
$$

and the field energy distributed in the volume $V$ in the form

$$
W=\int_{V} \frac{B^{2}}{2 \mu_{0}} d V=\frac{\mu_{0} I^{2} R}{4} k_{W},
$$

where $I$ is the total current of all windings, $k_{B}$ and $k_{W}$ are the dimensionless characteristics of the magnetic system.

Considering (1) and (2) as a system of two algebraic equations, the current $I$ and the large torus radius $R$ are expressed in terms of the initial parameters $W$ and $B_{m}$ as follows:

$$
I=\frac{W^{1 / 3} B_{m}^{1 / 3}}{\mu_{0}^{2 / 3}} k_{I}, \quad R=\frac{W^{1 / 3} \mu_{0}^{1 / 3}}{B_{m}^{2 / 3}} k_{R} .
$$

The corresponding dimensionless characteristics $k_{I}$ and $k_{R}$ in (3) take the form

$$
k_{I}=\frac{2 \pi^{1 / 3}}{k_{w}^{1 / 3} k_{B}^{1 / 3}}, \quad k_{R}=\frac{k_{B}^{2 / 3}}{\pi^{2 / 3} k_{w}^{1 / 3}} .
$$

Taking into account that the sum of the cross sections of the conductors of all coils is $=I / j_{m}$, the volume of the conductive material of the superconducting winding $V_{s c}=S \cdot l$ is

$$
V_{s c}=\frac{I R}{j_{m}} k_{l}=\frac{W^{2 / 3}}{j_{m} B_{m}^{1 / 3} \mu_{0}^{1 / 3}} k_{s c},
$$

where the introduced dimensionless characteristics will be

$$
k_{s c}=2 \frac{k_{l} k_{B}^{1 / 3}}{k_{W}^{2 / 3}}, \quad l=k_{l} R .
$$


From (5) it can be seen that with an increase in the energy capacity of an magnetic energy storage, the required volume of the superconducting winding increases as $V_{s c} \sim W^{2 / 3}$. The volume of steel structures of the mechanical holding system is proportional to the first power of the field energy $-V_{s t} \sim W[10,14]$. Therefore, at relatively low power consumption, within the limits of the values considered in the work, the volume of structural materials turns out to be much smaller than the volume of the superconducting winding $[9,14]$.

It follows from the above relations that such parameters as the size of the magnetic system, the total toroidal current, the volume of the superconducting material are determined not only by the stored energy of the magnetic field, but also by the dimensionless characteristics of the magnetic system $k_{W}, k_{B}, k_{l}$ and related characteristics $k_{R}, k_{I}, k_{s c}$.

In an idealized model of a toroidal current surface, any of the listed dimensionless characteristics $k_{i}$ depends only on the configuration of the torus section, which is characterized by a set of dimensionless initial parameters. For example, for a torus of a circular section, this may be the only parameter - the ratio of small $r=\left(\rho_{2}-\rho_{1}\right) / 2$ and large $R=\left(\rho_{2}+\rho_{1}\right) / 2$ (see Fig. 1) torus radii $\varepsilon=r / R-$ relative radial size of the torus section.

The dimensionless characteristics of a circular torus, expressed in terms of the dimensionless parameter $\varepsilon$, will be [4]

$$
\begin{gathered}
k_{B}=1 /(1-\varepsilon), \quad k_{W}=2\left(1-\sqrt{1-\varepsilon^{2}}\right), k_{l}=2 \pi \varepsilon, \\
k_{R}=\left[2 \pi^{2}(1-\varepsilon)^{2}\left(1-\sqrt{1-\varepsilon^{2}}\right)\right]^{-1 / 3}, \\
k_{s c}=4 \pi \varepsilon\left[4 \pi(1-\varepsilon)\left(1-\sqrt{1-\varepsilon^{2}}\right)^{2}\right]^{-1 / 3} .
\end{gathered}
$$

Systems composed of a set of momentless constant tension windings of a more complex $D$-shape form a torus, the section geometry of which is also described using one parameter [4]. It may be the same relative radial section size $\varepsilon$. To describe the section of a torus with racetrack windings, two independent dimensionless parameters are necessary [10]. An idealized model makes it possible to obtain visual results for determining the values of geometrical parameters at which one or another configuration has optimal indicators. Thus, the analysis shows that the minimum values of the large torus radius and the volume of the superconducting winding for the mentioned configurations of magnetic systems are achieved in the range of the dimensionless parameter $\varepsilon \sim(0.4-0.6)[10]$.

We now consider a magnetic system with a discrete toroidal winding in the form of a system of a limited number of coils with a rectangular section.

The transition from an idealized model to a model of a winding with individual coils greatly complicates the analysis. Now, the dimensionless characteristics $k_{B}$ and $k_{W}$, and hence $k_{R}, k_{I}, k_{s c}$, also depend on additional dimensionless initial values that characterize the geometry of the system: the number of coils $N$, the relative values of thickness $\Delta / R$ and the width $h_{c} / R$ of coils, as well as the parameter which characterizes the presence of a gap between the coils $k_{s t}=h_{c} / h_{s t} \leq 1$, where $h_{s t}$ is the maximum width of the coil with no gap, when $h_{b}=0$.

For a system with a discrete winding with additional data on the number of coils $N$ and the value of $k_{s t}$, the sectional dimensions of each coil $\Delta / R$ and $h_{c} / R$ are also to be determined by given magnetic energy values $W$ and the properties of the superconducting conductors $B_{m}$ and $j_{m}$. That is, the dimensions of the section of the coils depend on the initial parameters of the storage, and at the same time, these dimensions affect the value of the dimensionless characteristics $k_{R}, k_{I}, k_{s c}$ of the storage.

The most significant is that any dimensionless characteristic $k_{i}$ is determined not only by the parameters of the torus section, but also depends on the initial parameters of the storage $k\left(\varepsilon, \ldots, W, B_{m}, j_{m}, N, k_{s t}\right)$. This means that a parametric analysis cannot be carried out separately for the initial dimensional and dimensionless parameters. However, the task can be formulated not only as finding the mass and dimensional parameters for a particular storage capacity, but also based on obtaining corrections to the values of dimensionless characteristics that are valid for an idealized model. This allows to carry out a generalized analysis for the approximate values of quantities with a certain error, and to characterize its deviation by the value

$$
\beta_{i}=\frac{k_{i N}-k_{i}}{k_{i}},
$$

where $k_{i}$ is the value of the dimensionless characteristic when calculating with the help of an idealized model of a continuous current surface, $k_{i N}$ is the same characteristic of the system with separate coils.

During the calculations, the following features of the system with a discrete winding were taken into account.

First, each value of the mass-dimensional parameters and dimensionless characteristics were found as a result of solving the problem with the following initial parameters: $\varepsilon, W, N, k_{s t}, B_{m}, j_{m}$. Permissible values of the magnetic flux density and current density in the winding $B_{m}=5 \mathrm{~T}, j_{m}=4 \cdot 10^{7} \mathrm{~A} / \mathrm{m}^{2}$ were selected, which corresponds to the values for the wire based on the lowtemperature NbTi superconductor.

Secondly, it was taken into account that for real windings the position of a point on the perimeter of the coil section (see Fig. 1) with the maximum value of the magnetic flux density $B_{m}$ depends on the size of the section, i.e. is a function of the initial parameters. This point is shifted to a region near the angle of a rectangular section, and therefore the condition for finding its position was included in the system of equations for finding the geometry of the system.

Thirdly, the magnetic field of a system with discrete coils exists not only in a certain internal volume, as in an idealized model, but extends beyond its limits. Therefore, the calculation of the magnetic field energy was carried 
out using integration over the volume occupied by the currents in accordance with the expression:

$$
W=\frac{1}{2} \sum_{i} \sum_{k} W_{i k}=\frac{1}{2} \sum_{i} \sum_{k} \int_{V} \boldsymbol{A}_{i} \boldsymbol{j}_{k} d V,
$$

where $\boldsymbol{j}_{k}$ is the current density of one of current systems; $\boldsymbol{A}_{i}$ is the magnetic vector potential created by another (at $i \neq k$ ) or the same (at $i=k$ ) system in the region of current flow.

When performing calculations, the asymptotic methods for calculating the magnetic field of massive circuits with current, described in detail in [15], were used to reduce the required amount of calculations. An iterative calculation procedure was used to determine the dimensionless characteristics.

As an example, Fig. 2 shows deviations $\beta_{B}$ and $\beta_{W}$ for dimensionless characteristics, respectively, $k_{B}$ and $k_{W}$ of SMES with round-shaped coils depending on energy capacity at different values of relative radial size $\varepsilon$. In order to show the general trends of deviations $\beta_{B}$ and $\beta_{W}$, a wider range of values $\varepsilon=0.2-0.8$ was chosen as compared to the minimum values of the large torus radius and the volume of the superconducting winding.
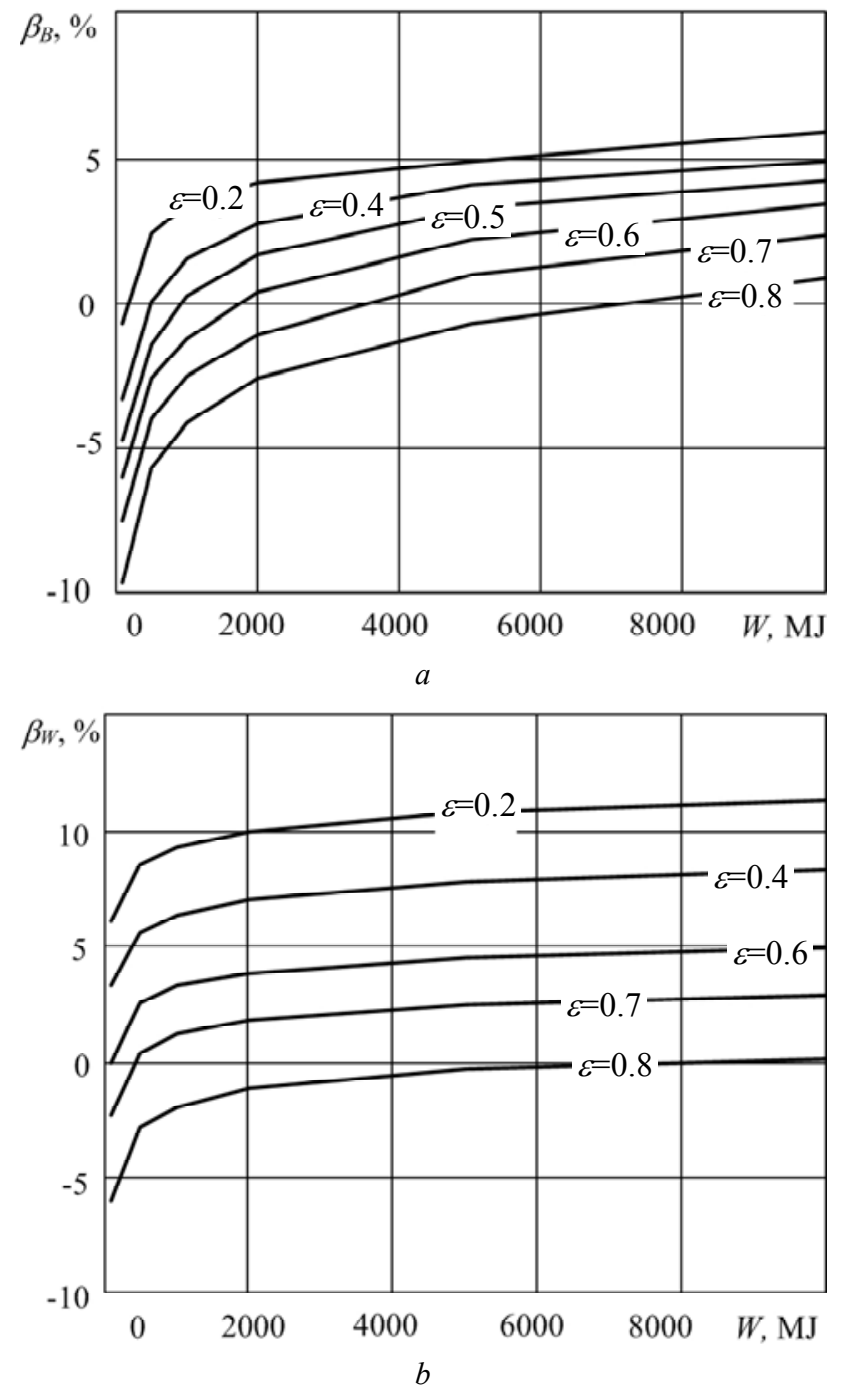

Fig. 2. Relative deviations $\beta_{B}$ and $\beta_{W}$ for the storage with round-shaped coils $\left(N=36, k_{s t}=1\right)$
Figure 3 illustrates the effect of the number of circular storage's coils on the value of deviation $\beta_{s c}$ from the value of the idealized model for the dimensionless characteristic $k_{s c}$, which determines the volume of the material of the superconducting winding. In this case, the calculation was carried out at a specific value of the energy capacity of SMES of $450 \mathrm{MJ}$, which is sufficient for the storage to perform the function of damping lowfrequency irregular power flow oscillations along the high-voltage transmission line [9].

From presented in Fig. 2 dependencies it is seen that in the considered range of energy capacity and a significant number of coils $N=36$, the calculation error for the idealized model does not exceed $\sim 10 \%$.

From Fig. 3 it can be seen that the error in calculating the volume of the superconducting winding also does not exceed $10 \%$ for storages with a smaller number of coils.

The indicated order of the error in calculating the mass-dimensional parameters of the magnetic system using the idealized model is also valid when varying other initial parameters for all the dimensionless characteristics under consideration. This indicates the possibility of using an idealized model at the first stage of the investigation. More accurate calculation can be performed after selecting approximate parameters of the storage.

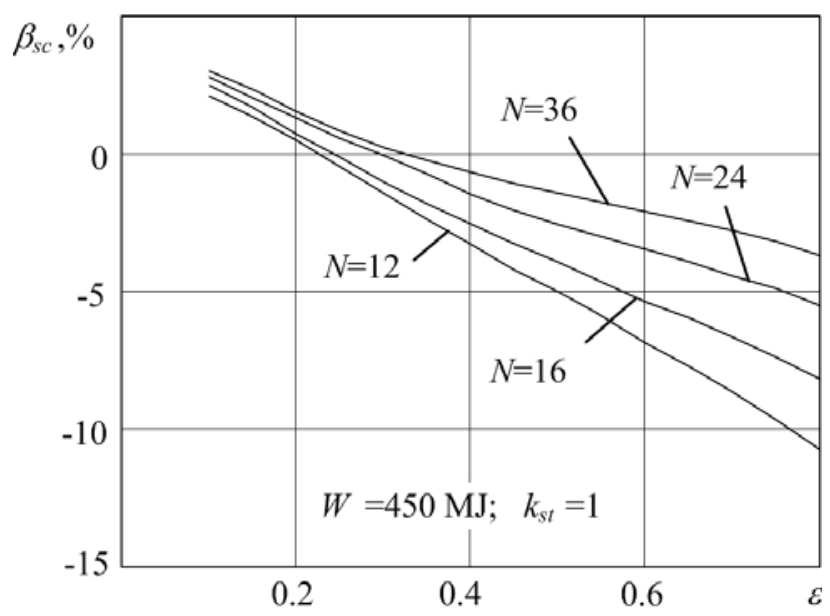

Fig. 3. Relative deviations $\beta_{s c}$ for the storage with round-shaped coils

The field of scattering of a toroidal system with a limited number of superconducting coils. Magnetic flux density created by the surface current flowing over the toroidal current surface has only an azimuthal component and is concentrated inside the toroidal volume, in other words, there is no field of scattering in the idealized model.

For a real magnetic system, which is a system of individual coils with axial lines located on the surface of the torus, the magnetic field extends beyond the toroidal surface. A qualitative picture of the magnetic flux density lines in the $x O y$ plane of the storage with eight coils is shown in Fig. 4. 


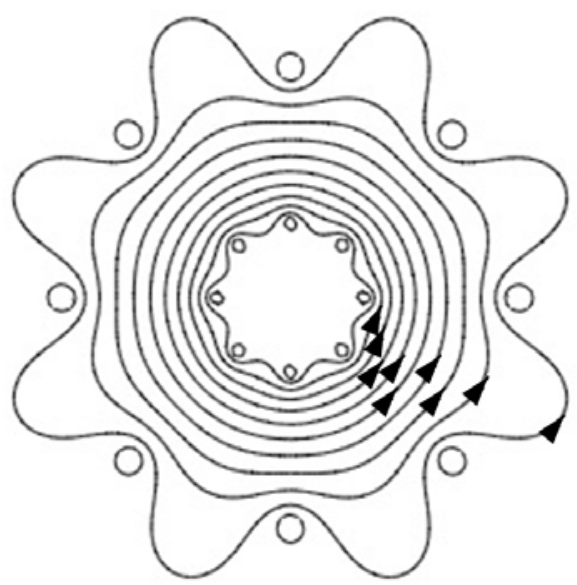

Fig. 4. Lines of the magnetic flux density

Outside the toroidal surface, only a «buckling» of the field in the region between the coils is shown for lines with a common magnetic flux density direction, which coincides with the field direction in the central part of the torus. However, for a field of scattering in areas adjacent to the planes in which the coils lie, the magnetic flux density vector has the opposite direction. Moreover, outside the toroidal winding, the averaged values along both directions are the same. This follows from the zero value of the circulation of the magnetic flux density vector along a circle of radius $\rho$ exceeding the outer radius of the torus $\rho>\rho_{2}+\Delta / 2$

$$
\oint_{l} \boldsymbol{B} d \boldsymbol{l}=\rho \int_{0}^{2 \pi} B_{\varphi} d \varphi=0,
$$

where $\varphi$ is the azimuth angle.

For definiteness in the investigation of the field of scattering, the calculation results are given for the distribution of the magnetic flux density along the radius $\xi$, passing between the coils in the $x O y$ plane, as shown in Fig. 1.

Since, as was shown, the geometrical dimensions of the magnetic energy storage, including the crosssectional dimensions of the coils, depend on the initial parameters, the distribution of the field of scattering was calculated, as before, for the storage's energy capacity of $W=450 \mathrm{MJ}$ and the properties of the superconducting wire based on NbTi.

Figure 5 shows the dependencies of the relative value of the magnetic flux density $B / B_{m}$ on the relative distance $\rho / \rho_{m}$ (solid curves) at points in space beyond the volume bounded by the toroidal surface for $\rho>\rho_{2}+\Delta / 2$ (see Fig. 1); $\rho_{m}$ is the distance from the vertical axis of the torus to the point at which the magnetic flux density takes the maximum value $B_{m}$. These dependencies make it possible to estimate the value of the field of scattering for different values of the relative size of the section of the torus $\varepsilon$ and, accordingly, different maximum radial sizes of the torus.

The flux density of the magnetic field of scattering for all $\varepsilon$ decreases sharply away from the surface of the toroidal storage. At small values of $\varepsilon$ near the toroidal surface, the value of the magnetic flux density is greater. This is explained by the fact that for small $\varepsilon$ the magnetic flux density within the relatively small transverse size of the torus, changing inversely to the radius, drops to smaller values for $\rho_{2}$ than for larger $\varepsilon$.

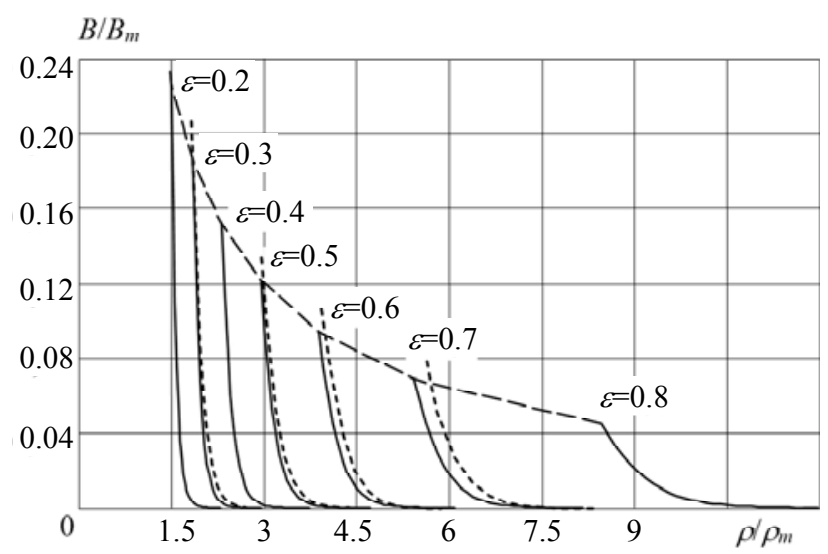

Fig. 5. Field of scattering of the toroidal magnetic system with the number of coils $N=16$ and $k_{s t}=1$

At the same time, the field decrease rate is the highest at small $\varepsilon$. This character of the dependence is due to the fact that at the outer radius of $\rho_{2}$ for small $\varepsilon$ the coils diverge relative to each other to a lesser extent than for large $\varepsilon$. The characteristic size $\Delta \rho$, on which the field of scattering significantly decreases, can be estimated as the distance between the coils on the radius $\rho_{2}$. So, from Fig. 1 it is shown that this distance is approximately

$$
\Delta \rho \approx 2 \rho_{2} \sin \frac{\pi}{N}-h_{c}=2 R(1+\varepsilon) \sin \frac{\pi}{N}-h_{c} .
$$

The relative distance from the toroidal surface on which the field decreases

$$
\frac{\Delta \rho}{\rho_{m}} \approx 2\left(\frac{1+\varepsilon}{1-\varepsilon}-k_{s t}\right) \sin \frac{\pi}{N},
$$

substantially depends on the relative cross-sectional size of the torus section $\varepsilon$, the number of coils $N$, and also on the coupling coefficient $k_{s t}$.

The values obtained from (13) are consistent with the data on the reduction of the field in the magnetic system with real-section coils shown in Fig. 5.

It is convenient to present the dependencies of the magnetic fields of scattering with a different number of coils for a specific value of $\varepsilon$. In Fig. 6, dependencies are presented for $\varepsilon=0.6$ and $k_{s t}=1$.

It can be seen that the external magnetic field decreases the faster with distance from the toroidal surface, the greater the number of coils used, in other words, the smaller the discreteness of the superconducting winding.

In the previous two cases, the calculations were carried out with the exact coupling of the coils near the radius $\rho_{1}-\Delta / 2$, and the discreteness was most pronounced at the radius $\rho_{2}$. However, it is almost impossible to ensure accurate coupling of coils in a particular system. Figure 7 presents the results of calculations on the effect of the coupling coefficient on the fields of scattering for $N=16, \varepsilon=0.6$ for different values of the coupling coefficient $k_{s t}=1,0.67$ and 0.5 . 


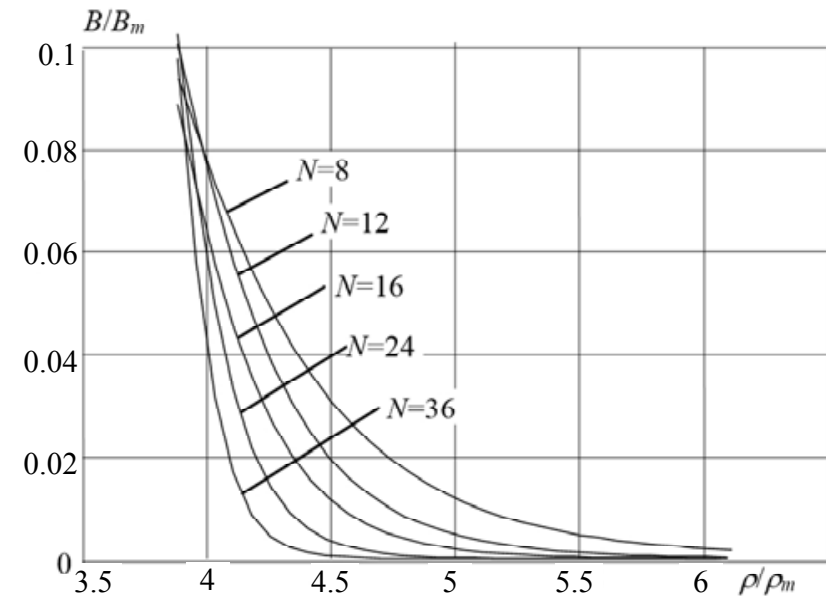

Fig. 6. The influence of the number of coils on the value of the field of scattering $\left(\varepsilon=0.6\right.$ and $\left.k_{s t}=1\right)$

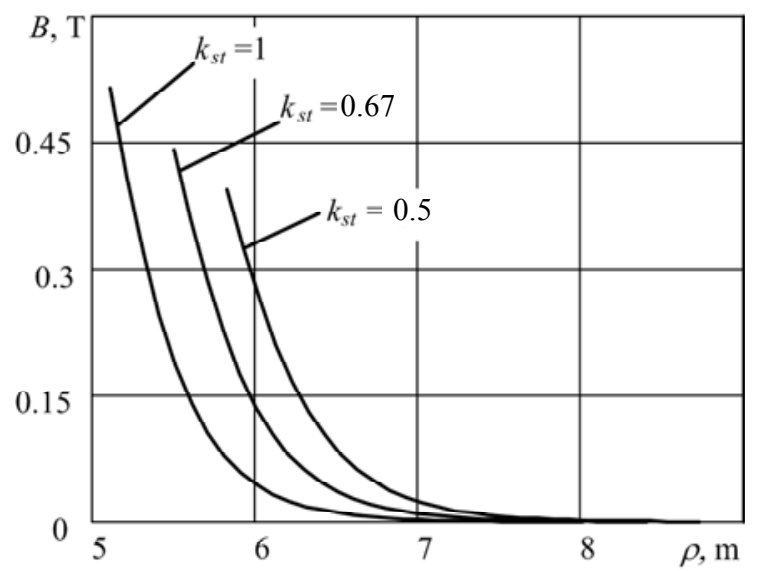

Fig. 7. Influence of the parameter $k_{s t}$ on the value of the field of scattering

The fields of scattering will be the smaller, the closer the coils are located to each other. In Fig. 7 dependencies are built in named units, which makes it possible to estimate the real values of the magnetic flux density and the distances covered by the fields for a storage with energy capacity of $W=450 \mathrm{MJ}$.

The calculation of fields of scattering using the complete model with a discrete winding is rather timeconsuming. To simplify the analysis, various approximate mathematical models can be used. However, as noted in [4], the nature of the approximate winding models significantly influences the results of the field calculation, especially near current-carrying parts. Thus, the use of current filaments as a model is associated with the appearance of features at the locations of the filaments, which introduces significant perturbations in the local field under consideration. However, the estimation of the field of scattering can be performed in the region between the coils at a certain distance from them.

Taking into account that the field of scattering decreases rapidly with distance from the winding, to estimate it in the $x O y$ plane, it is enough to use a simple plane-parallel model of a system of unidirectional current filaments. The position of the vertical current filaments is determined by the intersection of the axial lines of the coils with the plane. The calculation results for some values of the relative size of the sections of the torus $\varepsilon$ are shown in Fig. 5 by dashed lines. It can be seen that such a rough model allows, however, obtain preliminary results of the value of the field of scattering.

\section{Conclusions.}

1. In toroidal magnetic systems with a winding consisting of individual superconducting coils, it is advisable to carry out parametric analysis using dimensionless characteristics similar to those used for an idealized mathematical model of a toroidal current surface.

2. The dimensionless characteristics that show the influence of the geometrical configuration of the magnetic system on the dimensions of the toroidal winding, the mass or volume of the material of the superconducting winding, in the considered energy capacity range are only approximately independent on the total accumulated field energy and properties of the superconducting winding. At the same time, the relative deviations of the dimensionless characteristics calculated by the two models do not exceed $10 \%$, which makes it possible to apply an idealized model at the first stage of the development of a superconducting storage.

3. In contrast to the idealized model, the magnetic field of a toroidal system composed of individual coils spreads beyond the toroidal surface and decreases the faster, the smaller the relative radial size of the torus section, the greater the number of coils used and the closer they are to each other.

\section{REFERENCES}

1. Vyisotskiy V.S., Syitnikov V.E., Yliushyn K.V., Kovalev L.K., Kovalev K.L., Ehoshkyna L.A. Superconductivity in Electromechanics and Power Engineering. Electricity, 2005, no.7, pp. 31-40. (Rus).

2. Devotta J.B.X., Rabbani M.G. Application of superconducting magnetic energy storage unit in multi-machine power systems. Energy Conversion \& Management, 2000, vol.41, pp. 493-504. doi: 10.1016/S0196-8904(99)00100-4.

3. Matsukawa T., Nakamura H., Nomura S., Sato Y., Tsuji-Ito S., Shimada R. Conceptual design of SMES system equipped for IPP plant. IEEE Transactions on Applied Superconductivity, 2000, vol.10, no.1, pp. 788-791. doi: 10.1109/77.828349.

4. Thome R.J., Tarrh J.M. MHD and Fusion Magnets. Field and Force Design Concepts. New York, A Wiley-Interscience Publication, 1982. $316 \mathrm{p}$.

5. Duchateau J.L., Journeaux J.Y., Gravil B. Tore Supra Superconducting Toroidal Magnetic Field System. Fusion Science and Technology, 2009, vol.56, no.3, pp. 1092-1123. doi: 10.13182/FST09-A9170.

6. ITER Physics Basis. Nuclear Fusion, 1999, vol.39, no.12. doi: 10.1088/0029-5515/39/12/301.

7. Avramenko V.M., Aristov Yu.V., Vasetskiy Yu.M., Mazurenko I.L., Chernenko P.O. Some areas of effective use of superconducting magnetic energy storage (SPIN) in power systems of Ukraine. Technical electrodynamics. Thematic issue «Problems of modern electrical engineering», 2008, chapter 3, pp. 43-48. (Ukr).

8. Zhou X., Chen X.Y., Jin J.X. Development of SMES Technology and Its Applications in Power Grid. Proceedings of 
2011 IEEE International Conference on Applied Superconductivity and Electromagnetic Devices. Sydney, Australia, December 14-16, 2011, pp. 260-269. doi: 10.1109/ASEMD.2011.6145115.

9. Vasetsky Yu.M., Mazurenko I.L., Pavlyuk A.V. Damping of irregular low-frequency load fluctuations using a superconducting magnetic energy storage. Electricity, 2014, no.2, pp. 10-17. (Rus).

10. Mazurenko I., Pavlyuk A., Vasetsky Yu. Parameters of superconducting magnets with racetrack-shaped coils and support structure placed inside torus. Przeglad Elektrotechniczny, 2012, no.3a, pp. 67-69.

11. But D.A., Aliyevskiy B.L., Mazyrin S.R., Vasyukevich P.V. Nakopiteli energii [Energy storage]. Moscow, Energoatomizdat Publ., 1991. 400 p. (Rus).

12. Pavlyuk A. magnetic fields and parameters of toroidal superconducting magnets with limited number of coils. Works of the Institute of Electrodynamics of the National Academy of Sciences of Ukraine, 2013, no.34, pp. 94-105. (Ukr).

13. Dimitrov I.K., Zhang X., Solovyov V.F., Chubar O., Li Q. Rapid and Semi-Analytical Design and Simulation of a Toroidal Magnet Made With YBCO and MgB2 Superconductors. IEEE Transactions on Applied Superconductivity, 2015, vol.25, no.5, pp. 1-8. doi: 10.1109/TASC.2015.2448455.
14. Brechna H. Superconducting magnet systems. Berlin, Springer, 1973. 590 p.

15. Vasetsky Yu.M. Asimptoticheskie metody resheniia zadach elektrodinamiki $v$ sistemakh $s$ massivnymi krivolineinymi provodnikami [Asymptotic methods for solving electrodynamics problems in systems with bulky curvilinear conductors]. Kyiv, Naukova dumka Publ., 2010. 271 p. (Rus).

\section{Received 18.02.2019}

Yu.M. Vasetsky ${ }^{1}$, Doctor of Technical Science, Professor, I.L. Mazurenko ${ }^{1}$, Candidate of Technical Science,

S.L. Bondarevskyi ${ }^{2}$, Candidate of Technical Science, Associate Professor,

${ }^{1}$ The Institute of Electrodynamics of the NAS of Ukraine, 56, prospekt Peremogy, Kiev-57, 03057, Ukraine, phone +380443662562 ,

e-mail: yuriy.vasetsky@gmail.com

${ }^{2}$ Kryvyi Rih National University,

11, V. Matusevycha Str., Kryvyi Rih, 50027, Ukraine, phone +380673165975 ,

e-mail: parapet1979@googlemail.com

How to cite this article:

Vasetsky Yu.M., Mazurenko I.L., Bondarevskyi S.L. Parametric analysis and stray fields of toroidal superconducting magnetic energy storage. Electrical engineering \& electromechanics, 2019, no.3, pp. 30-36. doi: 10.20998/2074272X.2019.3.05. 